Résumés des conférences et travaux

\title{
Philologie et épigraphie hébraïques et araméennes
}

André Lemaire

\section{OpenEdition \\ Journals}

Édition électronique

URL : https://journals.openedition.org/ashp/167

DOI : 10.4000/ashp.167

ISSN : 1969-6310

Éditeur

Publications de l'École Pratique des Hautes Études

Édition imprimée

Date de publication : 1 octobre 2008

Pagination : 22-23

ISSN : 0766-0677

Référence électronique

André Lemaire, "Philologie et épigraphie hébraïques et araméennes », Annuaire de l'École pratique des hautes études (EPHE), Section des sciences historiques et philologiques [En ligne], 139 | 2008, mis en ligne le 19 novembre 2008, consulté le 12 juillet 2021. URL : http://journals.openedition.org/ashp/167 ; DOI : https://doi.org/10.4000/ashp.167 


\title{
PHILOLOGIE ET ÉPIGRAPHIE HÉBRAÏQUES ET ARAMÉENNES
}

\author{
Directeur d'études : M. André Lemaire, \\ correspondant de l'Institut
}

Programme de l'année 2006-2007 : I. 2 Rois 8 et s. : Israël et Juda au IXe s. av. J.-C., cycle d'Élisée. - II. Épigraphie ouest-sémitique : inscriptions inédites ou méconnues du Ir millénaire av. J.-C. au III ${ }^{e}$ s. apr. J.-C.

\section{2 Rois 8 et s. : Israël et Juda au IXes. av. J.-C., cycle d'Élisée}

Nous avons poursuivi et terminé cette année l'étude philologique et historique du cycle d'Élisée en le resituant dans son contexte social, économique et politique, à savoir le royaume d'Israël durant la deuxième moitié du $\mathrm{IX}^{\mathrm{e}} \mathrm{s}$. av. J.-C., période qui commence à être mieux connue aujourd'hui grâce à l'épigraphie ouest-sémitique.

2 Rois 8,16-29 fait partie de l'histoire synchronique présentant successivement les règnes de Yehoram et d'Akhazyahu, rois de Juda contemporains du règne de Yoram fils d'Akhab en Israël. Leurs règnes sont jugés négativement car, par Athalie petite fille d'Omri, épouse de Yehoram et mère d'Akhazyahu, ils se rattachaient à la « maison d'Akhab », expression dont on a l'équivalent dans la stèle de Mésha, roi de Moab. Cette présentation historique a conservé deux données importantes : la révolte et l'indépendance d'Édom et de Libnah et le fait qu'Akhazyahu se soit joint à Yoram d'Israël dans sa campagne contre le roi araméen Hazaël à Ramot-de-Galaad.

Les chapitres 9 et 10 rapportent le " coup d'état de Jéhu » en 841 av. n. è. Le récit est détaillé et rédigé, pour l'essentiel, peu de temps après les événements, probablement pour justifier la prise du pouvoir par le général Jéhu $(10,30)$ qui a éliminé la dynastie précédente, la " maison d'Akhab », avec l'appui de certains leaders religieux traditionnels (les « fils de prophètes » se rattachant à Élisée et les Rékabites). Pour ces derniers, Jéhu apparut comme celui qui « supprima d'Israël le Baal » $(10,28)$. Jéhu tua lui-même le roi Yoram d'Israël et fit exécuter sa mère Jézabel ainsi que le roi de Juda Akhazyahu, son neveu. Cependant, dans la stèle araméenne de Tel Dan, c'est le roi araméen Hazaël qui revendique l'exécution de Yoram roi d'Israël et d'Akhazyahu roi de Juda. Nous avons essayé de montrer que cette double revendication par deux textes de propagande royale pouvait s'expliquer historiquement et avait un parallèle dans la prise de pouvoir du roi d'Israël Osée, un peu plus d'un siècle plus tard. La dynastie de Jéhu allait durer près d'un siècle et commença dans un contexte politique très difficile : soumission au roi assyrien Salmanazar III puis au roi araméen de Damas, Hazaël, avec perte des possessions transjordaniennes (10,32-33 et stèle de Mésha).

Grâce à l'Athalie de Racine, 2 Rois 11 est célèbre dans la littérature française. Il s'agissait d'un changement de régence du jeune roi Joas. La reine-mère Athalie a été éliminée et remplacée par le prêtre yahviste Yehoyada. Ce coup d'état «nationa- 
liste » a entraîné l'élimination du culte de Baal en Juda et désormais les rois de Juda n'épouseront plus que des judéennes. La réforme cultuelle du roi Joas (12,5-17) doit être rapprochée de celle de Josias (22,3-9) et pourrait n'être qu'un midrash de cette époque. Les versets de type annalistique de 2 Rois $12,18-19$ et 13,3.7.22 révèlent la domination du roi araméen Hazaël sur tout le Sud du Levant à la fin du règne de Joas de Juda et durant tout le règne de Yoakhaz d'Israël. La fin de cette période est marquée par l'avènement du roi Joas d'Israël $(13,10)$, la mort d'Élisée $(13,14-21)$ puis celle de Hazaël $(13,24)$.

\section{II. Épigraphie ouest-sémitique : inscriptions inédites ou méconnues du I ${ }^{e r}$ mil- lénaire av. J.-C. au III ${ }^{e}$ s. apr. J.-C.}

La conférence d'épigraphie ouest-sémitique a d'abord été consacrée à l'épigraphie palmyrénienne. Nous avons réexaminé l'inscription publiée récemment par A. de Gross (« Two New Palmyrene Inscriptions », dans E. Cussini [éd.], A Journey to Palmyra. Collected Essays to Remember Delbert R. Hillers, Leyde, 2005 [CHANE, 22], p. 89-102) qui comporte deux dates (43 et 83/4 de n. è.) et plusieurs termes techniques d'architecture. Nous avons corrigé la lecture du début de la ligne 5 - où on peut lire BSYQ', vraisemblablement variante de BSLQ', " portique »- et celle de la fin de la ligne 8 où on peut lire BY[T], premier mot du syntagme bien attesté BYT 'LM'. Un des personnages nommés dans cette inscription, MLKW fils de ZBDBWL, se retrouve probablement sur une inscription funéraire inédite, gravée sur un cratère en haut relief. Nous avons alors étudié une inscription funéraire monumentale inédite de sept lignes, puis deux inscriptions cursives (dipinti) liées aux bustes funéraires de deux femmes. Enfin, nous avons lu et commenté une nouvelle inscription palmyrénienne gravée sur le bord d'un cratère en pierre datant de $154 / 5$ de n. è.

Après cette expérience d'épigraphie palmyrénienne, monumentale et cursive, nous nous sommes tournés vers de petites inscriptions plus anciennes : une pointe de flèche proto-phénicienne ( $\mathrm{XI}^{\mathrm{e}} \mathrm{s}$. av. n. è.), un petit fragment d'inscription de Qiryat Shmona (VI-IV s. av. n. è.), trois ostraca paléo-hébreux de Ramat Bet Shemesh (I. Milevski, « The Hebrew Ostraca from Site 94/21, Cave A-2, at Ramat Bet Shemesh », 'Atiqot, 50 [2005], p. 19-24), pour lesquels nous avons proposé quelques petites améliorations, ainsi que l'abécédaire de Tell Zayit (R. E. Tapy et alii, «An Abecedary of the MidTenth Cedntury B.C.E. from the Judaean Shephelah », BASOR, 344 [2006], p. 5-46) pour lequel nous proposons une datation paléographique approximative plus tardive (deuxième moitié du $\mathrm{X}^{\mathrm{e}} \mathrm{s}$. au début du VIII ${ }^{\mathrm{e}} \mathrm{s}$. av. n. è.) que celle de l'editio princeps.

Les dernières conférences ont été consacrées à l'épigraphie araméenne. Nous avons étudié un nouveau genre d'inscription araméenne : une inscription araméenne à l'encre écrite sur une tablette calcaire. Même si l'état de conservation de cette inscription à l'encre trouvée récemment à Tell Aushhariye (Syrie) rend la lecture de cette inscription très difficile, la paléographie permet de la dater vers 750-650 av. n. è. Plusieurs fragments de papyrus provenant des fouilles récentes de Saqqarah (Égypte) et comportant des inscriptions araméennes du $\mathrm{v}^{\mathrm{e}} \mathrm{s}$. av. n. è. ont aussi retenu notre attention : il s'agit apparemment de fragment de contrats et de documents administratifs remontant à la première occupation perse. 